\title{
Mild cognitive disorder and depression: treatment with combination of galantamine and escitalopram
}

\author{
Julio Zarra ${ }^{1 *}$, Luisa Schmidt ${ }^{2}$ \\ From $1^{\text {st }}$ International Congress on Neurobiology and Clinical Psychopharmacology and European \\ Psychiatric Association Conference on Treatment Guidance \\ Thessaloniki, Greece. 19-22 November 2009
}

\section{Background}

To evaluate the efficacy of galantamine-escitalopram combination in patients with Mild Cognitive Disorder and Depression. So there is a possible relation between the deficit of cerebral oxygenation and depression or relation between the serotonin system and cholinergic system in relation with disease comorbidity cognitivedepression.

\section{Objective}

To evaluate the therapeutic response in patients with comorbility between Mild Cognitive Disorder and Depression in treatment with Galantamine, Escitalopram and the two drugs in combination.

\section{Materials and methods}

A group of 300 patients with symptoms of Mild Cognitive Disorder and Depression (DSM IV-R criteria) were separated in 3 groups of 100 patients. Each group received different treatment in an 8 months period:

Group 1: Galantamine $16 \mathrm{mg} /$ day.

Group 2: Escitalopram $20 \mathrm{mg} /$ day.

Group 3: both drugs, same dose.

\section{Results}

The therapeutic response evaluated in Hamilton Scale for Depression(HAM-D), Montgomery and Äsberg Depression Rating Scale (M.A.D.R.S. ), Mini Mental State Examination (M.M.S.E.) and Global Clinical Impression (G.C.I.) scores during 8 months. In the third group who received the two drugs associated, had much better response than the others and "brain enhancer".

\section{Conclusions}

The group who received the combination of the nootropic agent Galantamine with antidepressant (SSRIs) Escitalopram had a relevant satisfactory therapeutic response (the best result), so there is a possible relation between the deficit in cholinergic systems and depression. Could be cerebral cholinergic systems deficit a generator of Depressive Disorder?

Attention and memory functions are closely tied to the cholinergic neurotransmitter system. The cholinergic system is one of the neurotransmitter systems implicated in the pathophysiology of mood disorders. Evidence suggests that during major depressive episodes, the cholinergic system is hypersensitive to acetylcholine.

\section{Author details}

${ }^{1}$ Servicio de Psiquiatría, Hospital Italiano de La Plata, Buenos Aires, Argentina. ${ }^{2}$ Servicio de Salud Mental, Hospital Centenario, Gualeguaychú, Argentina.

\section{Published: 22 April 2010}

Reference

1. Blesa R: Galantamine:Therapeutic effects beyond Cognition. Dement Geriatr Cogn Disord 2000, 11(suppl 1):28-34.

doi:10.1186/1744-859X-9-S1-S100

Cite this article as: Zarra and Schmidt: Mild cognitive disorder and depression: treatment with combination of galantamine and escitalopram. Annals of General Psychiatry 2010 9(Suppl 1):S100.

${ }^{1}$ Servicio de Psiquiatría, Hospital Italiano de La Plata, Buenos Aires, Argentina 